\title{
Effect of Prechemotherapy Steroid on Initial Tumor Load: An Outcome Indicator of Induction of Remission in Childhood Acute Lymphoblastic Leukemia (ALL)
}

\author{
MUHAMMAD TAWFIQUE ${ }^{1}$, RASHED JAHANGIR KABIR ${ }^{2}$, CHOWDHURY YAKUB JAMAL $^{3}$, \\ ABDUL MANNAN MIA ${ }^{4}$, NAJNIN UMME ZAKIA ${ }^{5}$
}

\begin{abstract}
Background: Treatment of Acute Lymphoblastic Leukemia (ALL) is mainly chemotherapy based. In the past outcome of treatment with polychemotherapy was dissatisfying. Recently success have improved as risk based polychemotherapy has been employed. Therefore in modern approach of the treatment of ALL of children assessment of risk factors has become a key issue. It has been observed in the studies abroad that response to prechemotherapy corticosteroid could be a clue to the good response to chemotherapy

Objectives: The objectives of this study were to see the effects of dexamethasone on initial tumor load and to observe the relationship of the effects of prechemotherapy dexamethasone on tumor burden and the outcome of Induction of Remission.

Materials and Methods: This was a prospective study carried out from January 2004 to June 2005 in the Department of Pediatric Hematology and Oncology at Bangabandhu Sheikh Mujib Medical University (BSMMU). All the cases between one to fourteen years of either genders were enrolled into the study after their confirmation as ALL. Tumor load was assessed before the beginning of prechemotherapy dexamethasone and after the day 7 of prechemotherapy dexamethasone. After reassessment of tumor load, polychemotherapy of Induction of Remission was begun. Bone marrow study was performed every seven days after starting Induction chemotherapy until the bone marrow remission was achieved. Then the effect of prechemotherapy dexamethasone on tumor load was compared with the outcome of Induction polychemotherapy. The results were analyzed maintaining standard procedure with SPSS version 10.0.
\end{abstract}

Results: $A$ total of 40 patients were enrolled into the study. Among them 21 were male and nineteen were female. Thirty were FAB L1 and ten were $L 2$ morphologically. Reduction of tumor load was evident as estimated by peripheral blast count together with hepatic and splenic mass. Response to prechemotherapy dexamethasone was good in 21 out of 28 patients with the WBC count below $50 \times 10^{9} / \mathrm{L}$ as compared to only 4 out of 12 with the WBC count $>50 \times 10^{9} / \mathrm{L}(P=0.013)$. Similarly, 21 in 24 in the group $<25 \times 10^{9} / \mathrm{L}$ of Initial Blast Cell count responded good as compared to 4 in 16 with $>25 \times 10^{9} / L$ Initial Blast Cell count $(P=0.000)$. Among the 25 good responders to prechemotherapy dexamethasone 24 went into remission within 7 days of induction and among the 15 poor responders only 6 went into remission within 7 days of induction $(P=0.000)$.

Conclusion: Response to pre-chemotherapy dexamethasone could be a strong guide to predict the outcome of induction chemotherapy and help in risk stratification of childhood Acute Lymphoblastic Leukemia.

Keywords: Prechemotherapy, initial tumor, ALL, Dexamethasone.

1. Associate Professor, Paediatric Haematology \& Oncology, Dhaka Shishu (Children) Hospital, Dhaka

2. Associate Professor, Paediatric Oncology, National Institute of Cancer Research \& Hospital, Dhaka.

3. Professor and Chairman, Paediatric Hematology and Oncology, BSMMU, Dhaka.

4. Professor and Former Chairman, Paediatric Hematology and Oncology, BSMMU, Dhaka.

5. Assistant Professor, Paediatric Cardiology, National Institute of Cardio-Vascular Disease, Dhaka.

Correspondence: Dr. Muhammad Tawfique, Associate Professor, Paediatric Haematology \& Oncology, Dhaka Shishu (Children) Hospital, Dhaka, E-mail: mtawfique@gmail.com
Introduction:

Leukemia is a disease resulting from the neoplastic proliferation of hemopoietic or lymphoid cells. It results from a mutation in a single stem cell the progeny of which form a clone of leukemic cells. Often there is a series of genetic alterations rather than a single event. Genetic events contributing to malignant transformation include inappropriate expression of oncogenes and loss of function of cancer suppressing genes. The cell in which the leukemic transformation 
occurs may be a lymphoid precursor, a myeloid precursor or pluripotent stem cells capable of differentiating into both myeloid and lymphoid cells. Acute leukemias are characterized by a defect in maturation leading to an imbalance between proliferation and maturation. Since cells of the leukemic clone continue to proliferate without maturing to end cells and dying there is continued expansion of the leukemic clone where immature cells predominate. ${ }^{1}$ Risk adapted polychemotherapy for children with acute lymphoblastic leukemia is the basis of success stories in modern clinical oncology. Identification of risk factors therefore was felt very important. For many years high leukemic tumor burden has been recognized as one of the most important independent risk factors. Recently many studies have demonstrated prognostic significance of blast cell reduction in peripheral blood to a 7-day prednisone and one intrathecal dose of methotrexate on day one as a parameter for early treatment response. According to some of the recent studies, response to prechemotherapy prednisolone is one of the strongest indicators of good prognosis. ${ }^{2,3}$ While looking for a reliable, available and a cheap tool for a risk based stratification of ALL cases, importance of the identification of the effect of prechemotherapy steroid on initial tumor load was felt. On this ground, it appeared very crucial to study the relationship of the effect of steroid on initial tumor load in children with ALL. Therefore this study was conducted to see the effects of dexamethasone on initial tumor load and to observe the effects of tumor burden on response to prechemotherapy dexamethasone.

\section{Materials and Methods}

This was a prospective hospital based study performed during the period from January 2004 to June 2005 in the department of Pediatric Hematology and Oncology at Bangabandhu Sheikh Mujib Medical University (BSMMU). All the cases admitted into the department with the clinical suspicion of ALL were investigated. The patients between one to fourteen years, irrespective of male or female, having been confirmed as ALL, were enrolled into the study. Those having previous history of taking steroid during this illness or with past history of chemotherapy, or with interrupted chemotherapy schedule during the $1^{\text {st }} 7$ days of induction of remission or any parent disagreeing to be included in the study were excluded.

Diagnosis of the cases was based on the history, Clinical examination and laboratory investigations. The investigations were full blood count, peripheral blood film study, LDH level, $x$-ray chest and the confirmation of the diagnosis by study of bone marrow. CSF (Cerebrospinal fluid) study was done after the confirmation and on the day one of beginning of prechemotherapy dexamethasone. Tumor load was assessed at diagnosis and before any leukemic therapy was started. Assessment was done by the measurement of liver and spleen (In centimeter) from the costal margins of the respective sides, WBC and blast cell counts in peripheral blood film. When total WBC count was above $50 \times 10^{9} / \mathrm{L}$ the condition was labeled as hyperleukocytosis. ${ }^{4}$ It was considered as high blast cell count as the blast cell was counted more than $25 \times 10^{9} / \mathrm{L}$.

Liver and spleen were measured with the help of a measuring tape, Palpable liver more than $2 \mathrm{~cm}$ from the right costal margin in the mid clavicular line was considered as hepatomegaly. ${ }^{4}$ Just palpable spleen or more than that was described as splenomegaly. ${ }^{5}$

All the patients were maintained with adequate hydration, maintained on alkaline urine and on oral allopurinol to prevent tumor lysis syndrome (TLS). Treatment was started with 7 days of monotherapy with oral dexamethasone and one intrathecal dose of methotrexate (MTX), cytosine arabinoside and hydrocortisone at day one. The first day of treatment was the day of the first administration of dexamethasone. The initial dose of dexamethasone was $2 \mathrm{mg} / \mathrm{sqm} /$ day on day one, $4 \mathrm{mg} / \mathrm{sqm} /$ day on day two and $6 \mathrm{mg} / \mathrm{sqm} /$ day from day three and onwards. Intrathecal MTX, cytosine arabinoside and hydrocortisone were given on day one along with oral dexamethasone as mentioned above. Assessment of response was done on the $8^{\text {th }}$ day of dexamethasone therapy. Reduction of size of liver and spleen were noted. Changes in WBC count and blast cell number were also noted down carefully. The number of leukemic blasts in the blood on day 8 was counted in PBF. The presence of $1 \times 10^{9} / \mathrm{L}$ blasts in PBF on day 8 was defined as a Dexamethasone poor response. (DPR) that less than $1 \times 10^{9} / \mathrm{L}$ leukemic cells was required to be classified as Dexamethasone good response (DGR). Response to induction was determined by the assessment of bone marrow status at the end of first 7 days of chemotherapy. 7 When the blast cell counts in the bone marrow was less than $5 \%$ it was considered as complete remission. Blast cell count in the bone marrow $5 \%$ or above was considered as marrow not in remission. Bone marrow in complete remission was considered as responded to chemotherapy and that not in remission as not in remission as not responded. ${ }^{6}$ 
All the data were subjected to statistical analysis according to standard procedure. SPSS version 10.0 was used for statistical analysis. To identify the correlation between two groups of values Pearson's bivariate correlation was performed. To compare the means and SEM of two different groups of ALL independent sample $t$ test or paired sample $t$ test was done, as required. Pearson's chi-square test was used to analyze the relationshipsbetween the response of leukemic tumor load to prechemotherapy dexamethasone and Initial WBC count and that with Initial Blast Cell count. Probability value "P value" less than 0.05 and $95 \%$ confidence intervals $(\mathrm{Cl})$ were used as the level of significances.

\section{Results}

A total of 40 patients were enrolled in this study. Among them 21 were male and 19 were female. As many as 24 patients were in the age group between 1 to 6 years, 10 between 7 to 10 years and the rest 6 above 10 years. Twenty four out of forty cases $(60 \%)$ were from rural areas and 16 cases $(40 \%)$ were 10 years (Table I).

Table-I

Age and sex Distribution of the Cases:

\begin{tabular}{lccc}
\hline Age & \multicolumn{2}{c}{ Sex } & Total \\
\cline { 2 - 3 } & Male & Female & \\
\hline 1 to 6 yrs & 15 & 9 & 24 \\
7 to 10 yrs & 4 & 6 & 10 \\
Above 10 yrs & 2 & 4 & 6 \\
\hline Total & 21 & 19 & 40 \\
\hline
\end{tabular}

According to morphological classification 30 out of 40 cases $(75 \%)$ were of $L 1$ and only $10(25 \%)$ were of L2 variety. None of the cases involved was L3 (fig1).

Hepatomegaly was found in all the cases but splenomegaly was found in $34(85 \%)$ of them. Data was tabulated in table II to summarize the reduction of initial tumor load following 7 days of prechemotherapy

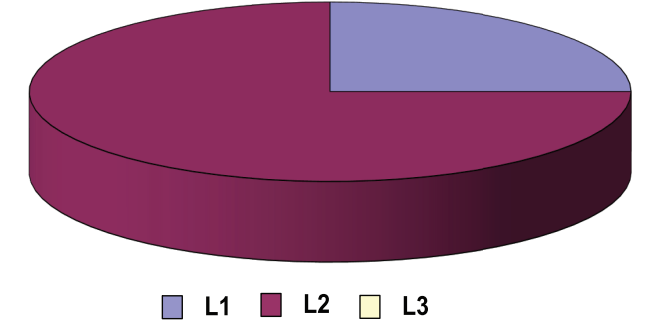

Fig.-1: Distribution of cases according to morphological classification (FAB) of the Cases.

dexamethasone by comparing the peripheral blast count, hepatomegaly and splenomegaly at diagnosis with their respective measurements at the end of 7 days of prechemotherapy dexamethasone. The minimum blast count at diagnosis as well as just after the 7 days dexamethasone therapy was 0 , maximum initial blast count was $112.5 \times 10^{9} / \mathrm{L}$ and maximum count after dexamethasone therapy at day 8 was $38.25 \times 10 \%$ L. Mean were $23.59 \times 10^{9} / \mathrm{L}\left(\mathrm{SEM}=4.83 \times 10^{9} / \mathrm{L}\right)$ and $4.91 \times 10^{9} / \mathrm{L}\left(\mathrm{SEM}=1.81 \times 10^{9} / \mathrm{L}\right)$ respectively (Table II). The reduction from higher initial blast counts to the lower one following 7 days of dexamethasone was proved to be statistically significant $(P=0.000 ; 95 \% \mathrm{Cl}$ 10.14 to 27.23 ).

Initial size of liver was compared with that following 7 days of dexamethasone therapy. Initial minimum measurement of liver was $4 \mathrm{~cm}$, maximum $10 \mathrm{~cm}$ and the mean was $5.7 \mathrm{~cm}(\mathrm{SEM}=0.20 \mathrm{~cm})$. After 7 days of dexamethasone prechemotherapy, these measurements came down to $1 \mathrm{~cm}, 7 \mathrm{~cm}$ and $4.27 \mathrm{~cm}$ $(\mathrm{SEM}=0.24 \mathrm{~cm})$ respectively. The reduction was proved statistically significant $(\mathrm{P}=0.000 ; 95 \% \mathrm{Cl} 1.06$ to 1.78$)$. Similarly, reduction of splenomegaly was proved significant $(P=0.000 ; 95 \% \mathrm{Cl} 1,527$ to 2.9127$)$ as showed by the comparisons. As in the initial so in the day 8 of dexamethasone therapy the minimum and the maximum measurements were the same 0 and 12 $\mathrm{cm}$ respectively. Yet, the fall of mean from $3.85 \mathrm{~cm}$ $(\mathrm{SEM}=0.53 \mathrm{~cm})$ to $1.63 \mathrm{~cm}(\mathrm{SEM}=0.43 \mathrm{~cm})$ indicated the difference(Table II).

Table-II

Reduction of initial tumor load after 7 days of prechemotherapy dexamethasone

\begin{tabular}{llcccccccc}
\hline & & Min & Max & Mean & SEM & t & df & P & $95 \% \mathrm{Cl}$ \\
\hline Peripheral & Initial & 0 & 112.5 & 23.59 & 4.83 & 4.42 & 39 & 0.0 & 10.14 to 27.23 \\
Blast count $\times 10^{9} / \mathrm{L}$ & Day 8* & 0 & 38.25 & 4.91 & 1.81 & & & & \\
Liver $(\mathrm{cm})$ & Initial & 4 & 10 & 5.7 & 0.20 & 8.10 & 39 & 0.0 & 1.06 to 1.78 \\
& Day 8* & 1 & 7 & 4.27 & 0.24 & & & & \\
Spleen $(\mathrm{cm})$ & Initial & 0 & 12 & 3.85 & 0.53 & 6.48 & 39 & 0.0 & 1.52 to 2.91 \\
& Day 8* & 0 & 2 & 1.63 & 0.43 & & & & \\
\hline
\end{tabular}

${ }^{*}$ Measurement immediately after the end of 7 days of prechemotherapy dexamethasone 
Table III depicted the relationship of initial WBC count with peripheral blasts at the end of 7 days of prechemotherapy dexamethasone. Among the 12 cases having initial WBC count equal to or more than $50 \times 10^{9} / \mathrm{L}, 8$ patients had poor response to prechemotherapy dexamethasone and 4 had good response to it. On the other hand when the initial WBC count was less than $50 \times 10^{9} / \mathrm{L}$ only 7 cases out of 28 showed poor response to dexamethasone and as many as 21 patients ended up with good response to dexamethasone at the end of 7 days' course of dexamethasone. The differences of response of blast cell count to prechemotherapy dexamethasone between the groups with hyperleukocytosis (50x10\%) L) and that lower than $50 \times 10^{9} / \mathrm{L}$ WBC was found statistically significant $(P=0.013)$.

\section{Table-III}

Relationship between Initial WBC count and the response to prechemotherapyDexamethasone:

\begin{tabular}{lccc}
\hline $\begin{array}{l}\text { Response to } \\
\text { Prechemotherapy } \\
\text { Dexamethasone }\end{array}$ & $\begin{array}{c}\text { Initial WBC count } \\
>50 \times 10^{9} / \mathrm{L} \\
(\mathrm{n}=12)\end{array}$ & $\begin{array}{c}<50 \times 10^{9} / \mathrm{L} \\
(\mathrm{n}=28)\end{array}$ & $\begin{array}{c}\text { Total } \\
(\mathrm{n}=40)\end{array}$ \\
\hline Poor & 8 & 7 & 15 \\
Good & 4 & 21 & 25 \\
\hline Total & 12 & 28 & 40 \\
\hline
\end{tabular}

$\chi^{2}=6.22, \mathrm{df}=1, \mathrm{P}=0.013$

Table IV presented here the relationship between initial blast count and the response to prechemotherapy dexamethasone. It could be observed here in the cases when initial blast cell was more than $25 \times 10^{9} / \mathrm{L} 12$ cases out of 16 responded poorly in contrast to the cases having initial blast cell count less than $25 \times 10^{9}$ / $L$ where only 3 out of 24 cases responded poorly. Good responders numbered only 4 in the former and 21 in the latter. This difference was found statistically highly significant $(P=0.000)$.

\section{Table-IV}

Relationship between Initial Blast Cell count and the response to prechemotherapy Dexamethasone

\begin{tabular}{lccc}
\hline $\begin{array}{l}\text { Response to } \\
\text { Prechemotherapy }\end{array}$ & $\begin{array}{c}\text { Initial blast count } \\
>25 \times 10^{9} / L \\
\text { Dexamethasone }\end{array}$ & $\begin{array}{c}\text { Total } \\
(\mathrm{n}=15)\end{array}$ & $\begin{array}{c}\text { To109/L } \\
(\mathrm{n}=25)\end{array}$ \\
\hline Poor & 12 & 3 & 15 \\
Good & 4 & 21 & 25 \\
\hline Total & 16 & 24 & 40 \\
\hline$\chi^{2}=16 . \mathrm{df}=1, \mathrm{P}=0.000$ & & &
\end{tabular}

Table $V$ showed the relationship between the response of initial blast count in the peripheral blood to prechemotherapy dexamethasone and response of bone marrow to induction chemotherapy. It could be evident here that in the dexamethasone poor response group, only 6 out of 15 went into remission by 7 days of initiation of induction. But in the group showing good response to dexamethasone, as many as 24 among 25 of the group went into complete bone marrow remission. Difference between the groups was also statistically highly significant $(P=0.000)$.

\section{Table-V}

Relationship between response of initial blast cell count (to prechemotherapy dexamethasone) and response of bone marrow (to induction chemotherapy)

\begin{tabular}{lccc}
\hline $\begin{array}{l}\text { Bone } \\
\text { Marrow }\end{array}$ & \multicolumn{3}{c}{ Response to Prechemotherapy Total } \\
Remission & $\begin{array}{c}\text { Dexamethasone } \\
(n=40)\end{array}$ & $\begin{array}{c}\text { Poor } \\
(n=15)\end{array}$ & $\begin{array}{c}\text { Good } \\
(n=25)\end{array}$ \\
\hline >day 7 of induction & 9 & 1 & 10 \\
<day 7 of induction & 6 & 24 & 30 \\
\hline Total & 15 & 25 & 40 \\
\hline
\end{tabular}

$\chi^{2}=16 . d f=1, P=0.000$

\section{Discussion}

The importance of getting a simple, cheap, usable and reliable prognostic indicator can not be overemphasized. It is important for stratification in the very early phase of indication of remission. Response of leukemic tumor burden to glucocorticoids is said to be the strongest predictor of outcome of the treatment of ALL. ${ }^{7,8}$ Most of the studies were carried out using prednisolone. Therefore, this study was designed to see the effect of dexamethasone on tumor load and their relationship with response to induction chemotherapy.

Dexamethasone was used in this study for 7 days before chemotherapy. Though most of the researchers studied on prednisone, dexamethasone was used during the phase of induction of remission replacing prednisone as used by a member of researchers. Monotherapy with dexamethasone significantly reduced the number of peripheral blast count during the 7 days time before chemotherapy $(P=0.000$, $95 \% \mathrm{Cl}=10.41$ to 27.23 ). It also significantly reduced 
the size of the liver $(P=0.000 ; 95 \% \mathrm{Cl} 1.069$ to 178$)$ and spleen $(\mathrm{P}=0.000,95 \% \mathrm{Cl}=1.52$ to 2.91$)$ during this prechemotherapy period. Dexamethasone here caused the reduction of the tumor load to a very significant level. Initial WBC count was seen to influence the response to dexamethasone. Response to dexamethasone was excellent (21/28) when initial WBC count was below $50 \times 10 \% / \mathrm{L}$. But when total leukocyte count was higher $\left(50 \times 10^{9} / L\right)$ the response was poor in most of the cases (8/12). This difference was proved statistically significant $(P=0.013)$. As illustrated above, high initial WBC count was associated with poor response to prechemotherapy dexamethasone.

This result is very consistent with that of BFM study group, as for a long time they employed the response to a 1-week single agent steroid treatment as prognostic factor. This method has proved valuable in detecting a very high-risk subgroup of children who needed intensive treatment to be cured permanently. ${ }^{9,10}$ Although there are other factors or variables involved as prognostic indicators in the treatment outcome of childhood acute lymphoblastic leukemias yet good early response to prednisolone remained as stand out indicator over the years until recently. ${ }^{11,12}$

In BFM studies toothe prednisone response emerged as the strongest predictor of outcome in childhood ALL. 8,9 Their results showed that the prednisone response was the strongest prognostic factor in infant ALL and might be used as a stratification factor in risk-adapted treatment protocols for ALL. Here in the present study dexamethasone was used and response to dexamethasone was considered as a variable.

Finally, it was well evident here that those responded well to prechemotherapy Dexamethasone went significantly earlier into remission following Induction Chemotherapy. It clearly indicated that Good Response to Prechemotherapy Dexamethasone could be a strong predictor of Good Response to the chemotherapy in Induction of Remission. It is true that now a daysimmunophenotyping and cytogenetics are gaining importance as the indicators for response to antilukemic treatment. But early remission in response to induction chemotherapy has been regarded as one of the strongest indicator of good outcome of the antileukemic treatment in childhood acute lymphoblastic leukemia. ${ }^{13,14}$ In the era when more sophisticated studies are on board yet these are not available everywhere and not affordable for everyone in this country. Therefore, indication of good response of tumor load to prechemotherapy dexamethasone can give us the indication of early remission in induction of remission phase of chemotherapy for childhood Acute Lymphoblastic Leukemia which could be one of the strongest prognostic indicators. ${ }^{15}$ In this context "Good response to Prechemotherapy Dexamethasone" could also give us the clue to stratify the leukemic cases on the basis of their risks as well as to predict on the outcome of the treatment of antileukemic chemotherapies also could be done on the merit of their going into remission at the end of induction of remission phase of risk basedantileukemic chemotherapy in Acute Lymphoblastic Leukemia in children.

\section{Conclusion}

It can be concluded from this observation that response to dexamethasone as prechemotherapy corticosteroid, could be a strong guide to predict the outcome of induction chemotherapy and help in risk stratification of childhood Acute Lymphoblastic Leukemia.

\section{References}

1. Bain BJ. Leukemia Diagnosis. $2^{\text {nd }} e d$. Oxford, Blackwell Science Ltd;1999:1-52.

2. Dordelmann M, Reiter A, Borkherdt A, Ludwid W-D, Gutz N, Viehmann S. et al. Prednisone Response is the Strongest Predictor of Treatment Outcome in Infant Acute Lymphoblastic Leukemia. Blood. 1999; 94: 1209-17.

3. Wei W, Chin X, Zou Y, Chang L, An W, Wan Y et al. Prediction of outcomes by early treatment responses in childhood T-cell acute Lymphoblastic leukemia: a retrospective study in China. Bio Med Central Pediatrics. 2015;15:80.

4. Kannavera J. Prognostic Factors in Childhood Acute Lymphoblastic Leukemia (dissertation), Finland, University of Helsinki 2001.

5. Bisset WM. Disorders of the Alimentary Tract and Liver. In: Campbell AGM, Mclntosh N, editors. Textbook of Pediatrics. $5^{\text {th }}$ ed. London, Churchill Livingstone, 1998; pp. 423-88.

6. French J, Camitta BM. The Spleen, In: Behrman RE, Kliegman RD, Jenson HB, editors. Nelson 
Textbook of Pediatrics. $16^{\text {th }}$ ed. Philadelphia, WB Saunders Co, 2000; pp. 1525-1527.

7. Steinherz PG, Gaynon PS, Breneman JC, Cherlow JM, Grossman NJ, Kersey JH, Cytoreduction and Prognosis in Acute Lymphoblastic Leukemia - the Importance of Early Marrow Response: Report from the Children's Cancer Group, J ClinOncol. 1996; 14: 389-98.

8. Lauten M, Moricke A, Beier R, Zimmermann M, Stanulla M. Prediction of outcome by early bone marrow response in childhood acute lymphoblastic leukemia treated in the ALL-BFM 95 trial: Differential effects in the precursor Bcell and T-cell Leukemia. Haematological. 2012;97:1048-56.

9. Schrappe M, Arico M, Harbott J, Biondi A, Zimmermann M, Conter V. Philadelphia Chromosome Positive $(\mathrm{Ph}+)$ Childhood Acute Lymphoblastic Leukemia: Good Initial Steroid Response Allows Early Prediction of a Favorable Treatment Outcome. Blood. 1998;92:2730-41.

10. Reiter A, Shrappe M, Ludwig W-D, Tiemann M, Parwaresch R, Zimmermann M, Schirg E, Henze G, Schellong G, Gadner H, Riehm H. Chemotherapy in 998 Unselected Childhood ALL
Patients, Results and Conclusion of the Multicenter Trial ALL-BFM 86. Blood. 1994;84:3122-33.

11. Fielding AK. Current Treatment of Philadelphia Chromosome-positive Acute Lymphoblastic Leukemia. Haematlogical. 2010;95:8-12.

12. Adele KF. Treatment of Philadelphia Chromosome-positive Acute Lymphoblastic Leukemia in adults: A broader range of options, improved outcome and more therapeutic dilemma. ASCO University Educational Book 2015.

13. Schrappe M, Reiter A, Ludwig W-D, Harboutt J, Zimmermann M, Hiddermann W, et al. Improved Outcome in Children Acute Lymphoblastic Leukemia Despite Reduced Use of Anthracycline and Cranial Radiotherapy: Results of Trial ALLBFM 90, German-Austrian-Swiss ALL-BFM Study Group. Blood. 2000; 95: 3310-22.

14. Hudson MM. Milestones in the curability of Pediatric Cancers. Journal of clinical Oncology. 2014;32:2391-97.

15. American Cancer Society. Prognostic factors in childhood leukemia; 2016; 13 Nov 2016.Available from www.cancer.org. 